\title{
RANCANG BANGUN MINIATUR TEMPAT PARKIR DENGAN METODE ELEKTRONIK PARKING PRICING (EPP) BERBASIS ARDUINO UNO
}

\author{
Gasa Raflianto, Priyo Sasmoko \\ Program Studi Diploma III Teknik Elektro \\ Fakultas Teknik Universitas Diponegoro \\ Email : gasarafli95@gmail.com
}

\begin{abstract}
Gasa Raflianto, Priyo Sasmoko, in this paper explain that design of miniature electronic methods parking place with parking pricing (EPP) based arduino uno created by looking at the problems that occur at this time, Berparkir is something that is often encountered in everyday dikehidupan. sometimes it is crucial to find the solution in order to provide convenience and comfort for the driver of the vehicle as well as the efficient use of parking space limitations. A lot of wasted time and sometimes quite a hassle just to queue entrance and exit of the parking lot during rush hour. Based on these problems, the authors provide a solution by designing a tool that can enable people to berparkir without having taken the trouble to enter and exit the parking lot without having to waste time and tenaga.Sistem is also supported by the Arduino Uno as the brain to process data from RFID, infrared is used to instruct the servo and servo motor is used as a parking portal.
\end{abstract}

Keywords:, Servo, RFID, Infrared Sensor

\section{PENDAHULUAN}

Semakin majunya perkembangan suatu kota, maka akan semakin banyak pula dibangun pusatpusat perbelanjaan dan perkantoran sebagai pusat aktivitas. Tempat parkir kendaraan tentunya menjadi syarat wajib yang harus dimiliki oleh pusat-pusat aktivitas tersebut. Bertambahnya jumlah kendaraan juga akan kian mengikuti pertumbuhan kota tersebut. Hal ini tidak diikuti oleh ketersediaan lahan parkir yang mampu mencukupi peningkatan volume kendaraan.Permasalahan tempat parkir sering menjadi masalah yang mengganggu, mulai dari tempat parkir yang manual dan kenyamanan pelanggan parkir. Untuk mengatasi permasalahan tersebut maka dibuatlah parkir dengan metode elektronik parking pricing yang bekerja secara otomatis. Perancangan alat ini diharapkan dapat membantu sebuah sistem otomatisasi yaitu parkir dengan RFID yang berfungsi untuk membuka portal. Dan penulis menggunakan sensor inframerah yang berfungsi untuk menggerakan servo dengan tujuan agar portal dapat menutup.

\section{Catu Daya}

Catu Daya atau power supply adalah suatu rangkaian yang berfungsi sebagai sumber daya untuk mengoperasikan rangkaian yang lain. Jenis rangkaian catu daya cukup banyak tetapi untuk rangkaian yang sederhana biasanya terdiri dari transformator, penyearah, filter, dan regulator. Prinsip dasar untuk memperoleh tegangan searah dapat dijelaskan dalam diagram blok seperti pada gambar 1 .

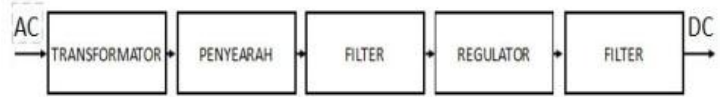

Gambar 1. Diagram Blok Catu Daya
Tegangan AC 220 Volt diturunkan tegangannya menggunakan trafo step down. Setelah itu tegangan disearahkan menggunakan penyearah tegangan atau dioda. Tegangan yang telah disearahkan tadi disaring melalui filter/kapasitor untuk meratakan ripple yang terjadi pada arus agar halus. Tegangan yang halus lalu diregulasi oleh regulator untuk menyesuaikan tegangan yang akan dituju / beban yang dituju, kemudian masuk ke filter lagi agar semakin halus.

\section{PWM (PULSE WIDTH MODULATION)}

Pulse Width Modulation (PWM) secara umum adalah sebuah cara memanipulasi lebar sinyal yang dinyatakan dengan pulsa dalam satu periode, untuk mendapatkan tegangan rata-rata yang berbeda. Bebarapa contoh aplikasi PWM adalah pemodulasian data untuk telekomunikasi, pengontrolan daya atau tegangan yang masuk ke beban, regulator tegangan, audio effect dan penguatan, serta aplikasi-aplikasi lainnya. Contoh aplikasi PWM ditunjukkan pada gambar 2.

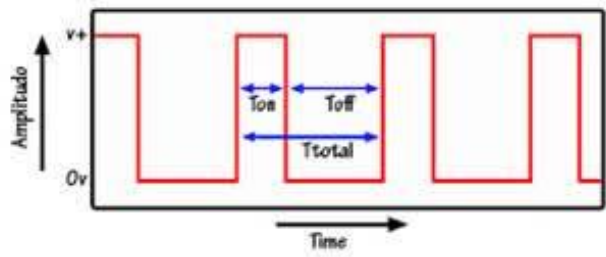

Gambar 2 Contoh Aplikasi PWM

Aplikasi PWM berbasis mikrokontroller biasanya berupa pengendalian kecepatan motor DC, pengendalian motor servo, dan pengaturan nyala terang LED. Oleh karena itu diperlukan pemahaman terhadap konsep PWM itu sendiri. 


\section{MOTOR SERVO}

Motor servo adalah motor dc yang dilengkapi rangkaian kendali dengan system closedback yang terintegrasi dalam motor tersebut. Pada motor servo posisi putaran sumbu (axis) dari motor akan di informasikan kembali ke rangkaian control yang ada di dalam motor servo. Motor servo disusun dari sebuah motor DC, gearbox, variabel resistor (VR) atau potensiometer dan rangkaian kontrol. Potensiometer berfungsi untuk menentukanbatas maksimum putaran sumbu (axis) motor servo. Sedangkan sudut dari sumbu motor servo diatur berdasarkan lebarpulsa yang pada pin kontrol motor servo. Bentuk fisik motor servo ditunjukkan pada gambar 3.

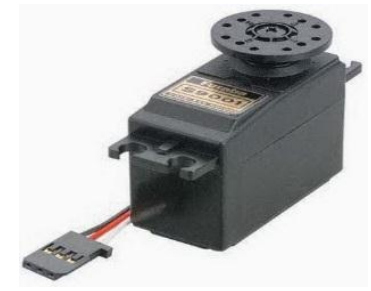

Gambar 3. Bentuk Motor Servo

\section{SENSOR INFRAMERAH}

Sistem sensor infra merah pada dasarnya menggunakan infra merah sebagai media untuk komunikasi data antara receiver dan transmitter. Sistem akan bekerja jika sinar infra merah yang dipancarkan terhalang oleh suatu benda yang mengakibatkan sinar infra merah tersebut tidak dapat terdeteksi oleh penerima. Keuntungan atau manfaat dari sistem ini dalam penerapannya antara lain sebagai pengendali jarak jauh, alarm keamanan, otomatisasi pada sistem. Pemancar pada sistem ini tediri atas sebuah LED infra merah yang dilengkapi dengan rangkaian yang mampu membangkitkan data untuk dikirimkan melalui sinar infra merah, sedangkan pada bagian penerima biasanya terdapat foto transistor, fotodioda, atau inframerah modul yang berfungsi untuk menerima sinar inframerah yang dikirimkan oleh pemancar. Bentuk fisik sensor inframerah ditunjukkan pada gambar 4.

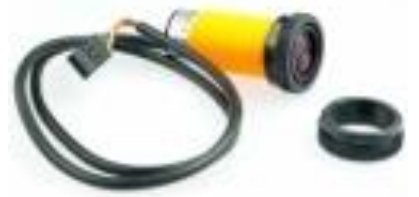

Gambar 4. Sensor Inframerah

\section{RFID (RADIO FREQUENCY IDENTIFICATION)}

Identifikasi suatu objek sangat erat hubungannya dengan pengambilan data. Salah satu metoda identifikasi yang dianggap paling menguntungkan adalah auto-ID atau Automatic Identification, yaitu metoda pengambilan data dengan identifikasi objek secara otomatis tanpa ada keterlibatan manusia. Auto-ID bekerja secara otomatis sehingga dapat meningkatkan efisiensi dan mengurangi kesalahan dalam memasukan data. RFID adalah salah satu dari berbagai teknologi yang dikelompokkan dalam Automatic Identification (Auto ID), seperti barcode, smart cards, voice recognition, serta identifikasi biometric seperti retinal scan, dan Optical Character Recognition (OCR). Teknologi RFID adalah sarana untuk mengumpulkan data tentang barang tertentu tanpa perlu sentuhan langsung atau melihat pembawa data, yaitu melalui penggunaan inductive coupling atau gelombang elektromagnetik. Sebagai pembawa data adalah microchip yang melekat pada antena (bersama- sama disebut reader atau tag), dan antena tersebut memungkinkan chip untuk mengirimkan informasi ke reader (transceiver) dalam kisaran yang diberikan dan dapat meneruskan informasi ke sebuah host komputer. Middleware (perangkat lunak untuk membaca dan menulis tag) dan tag dapat ditingkatkan dengan enkripsi data untuk aplikasi keamanan tingkat tinggi. Anti tabrakan algoritma juga dapat diimplementasikan untuk tag jika beberapa tag digunakan untuk dibaca secara bersamaan. Teknologi RFID mudah digunakan dan sangat cocok untuk operasi otomatis. RFID mengkombinasikan keunggulan yang tidak tersedia pada teknologi identifikasi yang lain. RFID dapat disediakan dalam perangkat yang hanya dapat dibaca saja (Read Only) atau dapat dibaca dan ditulis (Read/Write), tidak memerlukan kontak langsung maupun jalur cahaya untuk dapat beroperasi, dapat berfungsi pada berbagai variasi kondisi lingkungan, dan menyediakan tingkat integritas data yang tinggi. Pada sistem RFID umumnya, tag atau reader ditempelkan pada suatu objek. Setiap tag dapat membawa informasi yang unik seperti serial number, model, warna, tempat perakitan, dan data lain dari objek tersebut. Ketika tag ini melalui medan yang dihasilkan oleh reader RFID/RFID reader yang kompatibel, tag tersebut akan mentransmisikan informasi yang ada di dalamnya kepada RFID reader, sehingga proses identifikasi objek dapat dilakukan.

\section{BLOK DIAGRAM SISTEM}

Cara kerja pengoperasian RFID sebagai operating user parking area dengan metode elektronik parking pricing (EPP) berbasis Arduino uno ini terdiri dari beberapa blok komponen, yang selanjutnya melakukan proses yang dapat dilihat secara umum pada blok diagram yang ditunjukan oleh gambar 5 . 


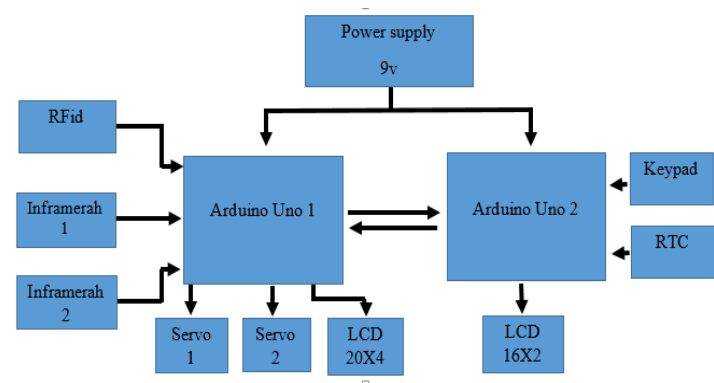

Gambar 5. Blok Diagram Sistem

\section{PENGUKURAN DAN PENGOPERASIAN Rangkaian Catu Daya}

Pengukuran rangkaian catu daya pada dasarnya bertujuan untuk mengetahui tegangan keluaran dari rangkaian catu daya agar tegangan keluaran dapat stabil sebagai catu daya pada masingmasing modul. Pada sistem ini menggunakan rangkaian catu daya dengan tegangan output sebesar $5 \mathrm{~V}$. Titik pengukuran yang dilakukan meliputi input trafo yaitu dari tegangan jala-jala PLN, output dari trafo yaitu tegangan PLN yang telah diturunkan oleh trafo step down, keluaran dioda sebagai keluaran setelah tegangan disearahkan, input dan output regulator, serta tegangan keluaran akhir.

Adapun langkah-langkah yang dilakukan untuk mengukur sistem minimum AVR ATmegal6 adalah sebagai berikut:

- Menghubungkan catu daya dengan jala-jala PLN.

- Mengukur tegangan tiap-tiap bagian yang telah ditentukan sebelumnya.

- Mencatat hasil pengukuran

Titik pengukuran catu daya diperlihatkan pada gambar 6. Hasil pengukuran ditunjukkan pada tabel 1.

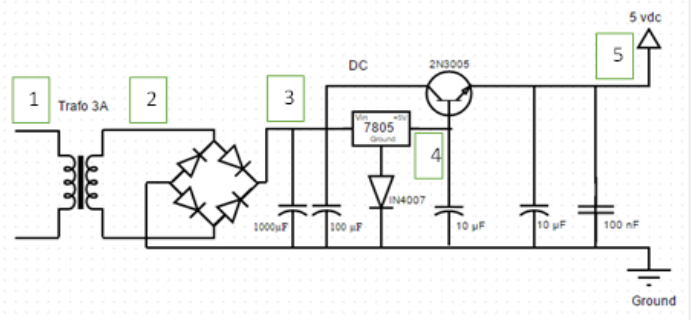

Gambar 6. Pengukuran Rangkaian Catu Daya

Tabel 1 Hasil Pengukuran Catu Daya

\begin{tabular}{|c|c|c|}
\hline No. & Bagian Yang Diukur & Tegangan \\
\hline 1 & Tegangan Input Trafo & $220 \mathrm{~V}_{\mathrm{AC}}$ \\
\hline 2 & $\begin{array}{l}\text { Tegangan Output Trafo } \\
\text { (a) }\end{array}$ & $12 \mathrm{~V}_{\mathrm{AC}}$ \\
\hline 3 & Tegangan Output Dioda & $14 V_{D C}$ \\
\hline 4 & $\begin{array}{l}\text { Tegangan Output LM } \\
7805+\text { Dioda }\end{array}$ & $5,7 \mathrm{~V}_{\mathrm{DC}}$ \\
\hline 5 & Tegangan output LM7805 & $5 \mathrm{Vdc}$ \\
\hline 6 & Tegangan Output 2n3055 & $5 \quad V_{D C}$ \\
\hline
\end{tabular}

\section{Rangkaian Sensor Inframerah}

Pengukuran Sensor Inframerah dilakukan ketika sensor pada keadaan tidak terhalang dan ketika ada halangan pada pancaran cahayanya. Hasil pengukuran ditunjukan pada tabel 2 .

Tabel 2. Pengukuran Sensor Inframerah

\begin{tabular}{ccc}
\hline Sensor & $\begin{array}{c}\text { Tegangan } \\
\text { Mendeteksi } \\
\text { (Terhalang) }\end{array}$ & $\begin{array}{c}(\mathbf{V}) \\
\text { Tidak Mendeteksi } \\
\text { (Tidak Terhalang) }\end{array}$ \\
\hline IR 1 & $0,4 \mathrm{v}$ & $4,6 \mathrm{v}$ \\
IR 2 & $0,4 \mathrm{v}$ & $4,6 \mathrm{v}$ \\
\hline
\end{tabular}

\section{Rangkaian Motor Servo}

Pengukuran motor servo dilakukan guna mengetahui apakah motor servo bekerja sesuai yang diharapkan. Yakni ketika RFID dan Inframerah menginginkan portal dibuka dan ditutup, kemudian pergerakan sudut putaran motor servo sudah sesuai dengan pengaturan pada program atau tidak. Titik pengukuran ditunjukkan pada gambar 7 sedangkan hasil pengukuran disajikan pada tabel 3dan 4 .

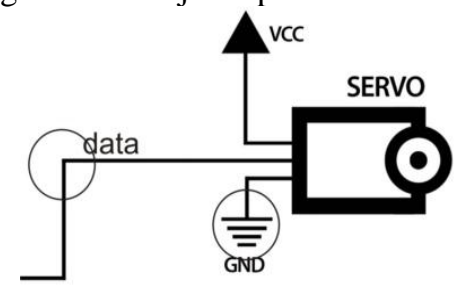

Gambar 7. Pengukuran motor servo

Tabel 3. Pengukuran Motor Servo

\begin{tabular}{ccc} 
No & Bagian yang diukur & Tegangan \\
\hline 1 & VCC & 4,8 VDC \\
2 & GND & O VDC \\
\hline
\end{tabular}

Tabel 4. Pengukuran Duty Cycle

\begin{tabular}{ccc} 
No & Sudut & Duty Cycle \\
\hline 1 & $0^{\circ}$ & $6,25 \%$ \\
2 & $10^{\circ}$ & $6,39 \%$ \\
3 & $45^{\circ}$ & $6,45 \%$ \\
4 & $80^{\circ}$ & $7,358 \%$ \\
5 & $90^{\circ}$ & $7,49 \%$ \\
6 & $180^{\circ}$ & $8,743 \%$ \\
\hline
\end{tabular}

\section{Pengujian Sistem}

Dalam pengambilan data pengujian alat pengoperasian RFID sebagai operating user parking area dengan metode elektronik parking pricing $(E P P)$ berbasis Arduino uno dapat diperoleh datadata hasil pengukuran di atas, selain itu dari pengujian sistem juga diperoleh data mengenai sistem dalam bekerja. Maka dari itu penulis menguji kerja alat dengan beberapa sampel. Hasil pengujian ditunjukkan pada tabel 5 dan 6 . 
Tabel 5. Jarak Baca RFID Terhadap Tag

\begin{tabular}{|c|c|c|}
\hline Jarak Baca & Keterangan & Kondisi \\
\hline $1 \mathrm{~cm}$ & Terbaca & $\begin{array}{c}\text { Palang } \\
\text { Membuka } \\
\text { Palang }\end{array}$ \\
\hline $1,5 \mathrm{~cm}$ & Terbaca & $\begin{array}{l}\text { Membuka } \\
\text { Palang }\end{array}$ \\
\hline $2 \mathrm{~cm}$ & Terbaca & $\begin{array}{l}\text { Membuka } \\
\text { Palang }\end{array}$ \\
\hline $2,5 \mathrm{~cm}$ & Terbaca & $\begin{array}{l}\text { Membuka } \\
\text { Palang }\end{array}$ \\
\hline $3 \mathrm{~cm}$ & Terbaca & Membuka \\
\hline $3,5 \mathrm{~cm}$ & Tidak Terbaca & Palang Tertutup \\
\hline $4 \mathrm{~cm}$ & Tidak Terbaca & Palang Tertutup \\
\hline
\end{tabular}

Tabel 6. Pengujian Tag RFID

\begin{tabular}{|c|c|c|}
\hline $\begin{array}{l}\text { Nomor } \\
\text { Kartu }\end{array}$ & Kondisi & Status \\
\hline A1E0F255 & Terdaftar & Cocok \\
\hline F33BF455 & Terdaftar & Cocok \\
\hline 55DDF255 & Terdaftar & Cocok \\
\hline 45B3F255 & Belum Terdaftar & $\begin{array}{l}\text { Tidak } \\
\text { Cocok }\end{array}$ \\
\hline $36 \mathrm{E} 6 \mathrm{~F} 255$ & Belum Terdaftar & $\begin{array}{l}\text { Tidak } \\
\text { Cocok }\end{array}$ \\
\hline
\end{tabular}

Pada proses pengukuran rangkaian modul RFID terdapat beberapa langkah yang harus dilakukan, yaitu sebagai berikut :

- Menghubungkan masukan rangkaian modul RFID dengan catu daya $5 \mathrm{~V}$.

- Mengukur tegangan pada saat modul RFID tidak didekati tag.

- Mengukur tegangan pada saat modul RFID didekati tag.

- Mencatat semua hasil pengukurannya.

\section{KESIMPULAN}

Dalam penelitian ini dapat diambil beberapa kesimpulan sebagai berikut :

- $\quad$ RFID akan bekerja jika tag RFID terbaca oleh reader dan dikirim ke arduino 1 kemudian dikirim lagi ke arduino 2 untuk diproses dengan dengan status kartu terdaftar atau tidak jika terdaftar arduino 2 akan mengirim perintah ke arduino 1 untuk membuka portal

- Sensor inframerah yang aktif memberikan perintah terhadap mikrokontroler untuk mengaktifkan servo menutup portal.

- Motor servo dapat membuka portal dengan pulsa 1,75 dan akan menutup jika diberi pulsa $1,28 \mathrm{~ms} \mathrm{~ms}$.

\section{DAFTAR PUSTAKA}

1 Anonim. Sensor. 5 agustus 2015. https://id.wikipedia.org/wiki/Sensor

2 Isyanto, Jazi Eko. 2014. Pengantar Elektronika dan Instrumentasi Pendekatan Project Arduino dan Android. Yogyakarta: ANDI

3 Koestoer, Raldi Artono.2004. Pengukuran Teknik. Jakarta: Departemen Teknik Mesin Fakultas Teknik Universitas Indonesia.

4 Massimo dkk., Arduino/Genuino Uno, 29 juli 2015.

5 Purnama, Agus, Kapasitor, 28 juli 2015

6 Purnama, Agus, motor servo, 28 juli 2015

7 Varlag,Zum, RFID, 28 juli 2015

8 Van Vlack. Lawrench, Ilmu dan Teknologi Bahan, Erlangga, hal 186

9 Zona elektro, Pulsa kendali motor servo, 28 juli 2015

10 Zona elektro, Komponen led Inframerah, 27 juli 2015. 